\title{
Study of the Effects of Communication Management on Infrastructure Projects in Jamaica
}

\author{
Sean Parham \\ Maintenance Department, Ministry of Health \\ Ministry of Health $(\mathrm{MoH})$ \\ Kingston, Jamaica \\ sparhamus@yahoo.com
}

\author{
Yan $\mathrm{Li}^{*}$ \\ International Business School \\ Yunnan University of Finance and Economics \\ Kunming, China \\ cyliyan2002@163.com
}

\begin{abstract}
Project Professionals require the transfer of relevant and appropriate information to the correct persons at all stages of a project in order to produce a structure as per specifications, on time and within budget to meet the clients' needs. Hence, the use of an applicable technique for information transfer and communication channels for infrastructural problem solving.So as to completely understand communication within the Jamaican building sector/industry, particularly communication on Infrastructure Projects, this study aims at ascertaining the effects of communication management on Infrastructure Project delivery in Jamaica regarding quality, cost overruns and time.
\end{abstract}

A quantitative approach was utilized by administering questionnaires as data collection would yield more results leading to a greater number of participants. A sample size of one hundred and forty specialists involved in infrastructure projects was obtained. Thereby, the findings could be generalized and applied to other locations. The primary data was analyzed with respect to theoretical data gathered. The existing communication process was examined through questionnaire survey where Relative Importance Index (RII), Frequency Index (FI) and IBM SPSS 23 were used for data analysis. This study recognized that there is a high level of appreciation regarding the importance of communication management on Infrastructure Projects in Jamaica. There are numerous recognized communication channels within the building sector especially between Grades 12 contractors, Project Managers, Civil Engineers, Architects, Quantity Surveyors, Structural, Mechanical and Electrical Engineers. However, difficulties still exist regarding effective and efficient communication management. This comprises of the following:

Poor listeners, Poor leadership, Imprecise communication objectives, Vague channels of communication, Unsuccessful reporting system, Ineffectual communication between specialist involved in the project, Labeling or Stereotyping and Linguistic complications.Lastly, this study acknowledged that ineffective communication management negatively impacted projects, resulting in delays, cost overrun and abandonment. However, it is also observed that effective communication management positively influence the functioning of infrastructure project professionals in the Jamaican context.Hence, prior to the implementation of any infrastructure project, clearly established and effective communication management structures alongside management structure is of utmost importance and needs to be scheduled by infrastructure project professionals. This will result in the improvement of communication and effective implementation of infrastructure projects.The skills for an effective communication management regarding infrastructure projects are making decision and solving problems, listening, meetings, motivation, team development building, management of conflict, explaining and writing.

Keywords-communication management; effects of communication; infrastructure projects in Jamaica

\section{INTRODUCTION}

Proficiency and Effectiveness in infrastructure projects are greatly dependent on the value of the connection between the clients, contractors, sub-contractors, and professionals. According to [1] issues in infrastructure projects are related to communication management issues.

According to [2] Infrastructure projects have numerous phases that are dependent on the experts conveying suitable and pertinent data in order to produce designs that can be constructed and also the client's specifications are met. Whilst infrastructure projects unfold and the designs are realized, information in varying forms such as illustrations, requirements and methods of construction must be transferred from one expert to another. That is data must be conveyed and comprehended in order for the numerous phases within the project can be constructed to achieve the intended purpose and the needs of the client. The professionals primarily involved in infrastructure projects are Quantity Surveyors, Architects, Project Managers, Structural, Mechanical and Electrical Engineers, Contractors and Sub-Contractors.

With regards to this research, Communication is the sharing, retrieval, managing and understanding of data. Which can either be expressed orally, non-verbally, enthusiastically, submissively, officially, unofficially, intentionally, or unintentionally [3].

A major impediment that a company encounters is the resolution of the issue of the flow information, be it sideways, downwards, and upwards and is sometimes referred to as communication management. The utilization of suitable communication management methods and channels to solve construction and design glitches are vital. In order to totally realize and comprehend the difficulty of communication 
management on Infrastructure projects in Jamaica, the subsequent questions have been crafted for exploration; How project professionals carry out communication management on infrastructure projects? The value placed on communication by the project professionals on Infrastructure Projects? How communication management affects project delivery, project quality and cost overruns?

Research regarding flaws and inadequacies in constructed structures, including during the construction stage signifies that several of the causes stem from the project planning phase, that is, in the management and information dissemination during the building's construction, and in the poor quality of the contractors' work [4][5].

According to [6] some of the deficiencies associated with construction sector is related to communication issues, for instance, an inadequately detailed drawing; contractors and sub-contractor's not given correct instructions or the required technical information is unavailable. How project professionals gather and distribute information in a timely manner when working on infrastructure projects in Jamaica is what is uncertain. This research seeks to eliminate the gaps or significant lack of information in this area of infrastructure projects in Jamaica.

A methodical literature review concerning project communication and issues regarding successful communication within infrastructure project was analyzed. Literature involving risks, which also included ineffective communication within infrastructure projects, were retrieved from the Internet, journals, and newspaper articles. Documents associated to communication on infrastructure projects, publications highlighting issues of ineffective communication and looking at improving communication procedure for infrastructure projects were chosen. Publications on techniques and tools used in communication management at present and future research required were selected. To have a good understanding of communication on infrastructure projects, methods of communication, tools, trends, types, methods and plan are reviewed through literature study.

A key component within businesses and professions that would require a considerable amount of thought and management so as to be effective would be communication. As stated in [7] the communication process involves the coming together of persons from which pertinent information is developed and communicated to the relevant persons. In adding to this [8] definition of communication states:

" ... the process of conveying messages that is facts, ideas, attitudes, opinions, from one person to another so that they are understood."

Infrastructure projects offers an environment where communication has a important part that is believed to be a inestimable prerequisite which will allow professionals to function properly. The chief purpose for communication management is that it is vital in infrastructure projects because these projects relay upon enormous volumes of material being transferred, particularly at a fast pace and of great amount with efficacy in order to adhere to the requirements of infrastructure projects in this extremely aggressive business [9][10].
In conjunction numerous professionals and the makeup of the industry, requires that they meet on a regular basis, pooling their knowledge and ideas whilst operating in unison on infrastructure projects necessitate wholesome communication management. Let's consider, crucial communication on an infrastructure project may include contractors, workforces, collaborators and customers to continuously communicate so as to achieve the goals relating to the infrastructure projects [11] [12]. According to (e.g. [12][13]) to be exact, it comprises numerous specialists at the project commencement stage, until conclusion, with the inclusion of engineers, organizers, designers, contractors, etc. Keeping in mind that the number of specialists involved, the requirement for appropriate and applicable communication increases importance, as different specialists in the different areas of expertise, each managing distinctive components within the project, intersecting with regards to comprehension and stages of experience.

As highlighted: "Communication in construction is a complex business due to the sheer multiplicity of potential stakeholders: government, investors, joint venture parties, local authorities and residents to name a few" [14].

Complications in communication found within this stage alludes to the circumstance that collaboration between specialist is necessary and is usually for short time spans there by amassing the difficulty of transmission of the data [10].

\section{A. Communication Defined}

Communication is the sharing, retrieval, managing and understanding information. That can be expressed orally, nonverbally, enthusiastically, submissively, officially, unofficially, intentionally, or unintentionally [15].

Successful exchange of information is a critical element of project communication management. Effective communication forms a connection amongst varied participants involved in a project, linking varying ethnic and structural backgrounds, a wide cross section of expertise and numerous viewpoints and interests in the execution of the project [3].

Communication is described by [16] as follows: "Communication is defined as a transaction. People work together to create meaning by exchanging symbols. People have to ensure they share the same meaning when they use words."

Communication is described by Trenholm and Jensen [17] as: "The transfer of meaning; a response of an organism to a stimulus; the process through which people make sense of things and share this with others; the transmission of information, ideas and emotions; an act initiated by individuals in which he or she seeks to discriminate and organize cues to orientate themselves in the environment; and a mechanism to influence the environment."

\section{B. The Significance of Communication}

Communication is a vital factor of any work, trade or in this case infrastructure projects, in light of its intricacies, communication within the infrastructure projects are extremely important. One important reason for this is the need for fulfillment with the building codes, legislature and guidelines, such as the Jamaican Building Code and Occupational Safety 
and Health Association Regulation (OSHA), to name a few. For example, communication, could be expressed utilizing onsite health and safety signs and instructions or meetings as poor communication in this situation could lead to devastating effects as persons could be critically or gravely wounded. In fact, the building sector for which infrastructure projects are apart has an unfortunate characteristic of how specialists and corporations transfer data [17]. The importance of communication is not only with regards to health and safety matters but is also of significant importance in infrastructure projects. According to (e.g. [12][13][18]) it's a matter of competence and efficiency in completing the project within time, budget and per specifications which can be accredited to thorough communication management at the various levels, so as to evade disappointing outcomes. The [19] publication emphasized such problems, asserting that several of the flaws in the UK construction industry are as a result of information not being proficiently communicated or employed, resulting the industry incurring an estimated cost of Twenty Billion Pounds (£20 billion) annually [19].

\section{Effective Communication}

One of the analytical attainment element in project management as per Project Management Institute (PMI) Pulse research is effective communication with all stakeholders, 55 percent of Project Managers are in agreement [20]. Project communication effectiveness is simply the correct information reaching the designated party at the appropriate time and in the utmost cost-effective way. In order to pursue project goals communication is the key element for ensuring that members of the team, stakeholders, and managers are informed and are kept on track, also to identify challenges, risks, misinterpretations, and any other factors that may impede project success. Effective communication is one of the key elements of the effectiveness teams both in conventional and virtual teams [20].

A study regarding the key elements contributing to a projects success 'effective communication' is one of the four most significant elements, including 'management support', 'clear purpose and goals' and 'stakeholders participation' [21]. Nguyen states that successful communication methods, suitable management styles are key success elements for constructing and handling high performance global virtual teams [21].

Effective communication is a critical element of project communication management. Communication that is effective forms connections amongst varied stakeholders within an endeavor, linking varying ethnic and organizational upbringings, a wide cross section of expertise and numerous viewpoints and attention to the project implementation [3].

Project managers and project team members have been estimated to spend approximately ninety percent $(90 \%)$ of their time involved in communication, that is conferences, inscribing and analyzing reports, emails and conversing with project stakeholders [22]. As stated by [22] status reports, monthly reports, change reports, and project communication plan are documentation that can be used to successfully communicate. The mediums of agendas and minutes were also added by [23].
As stated by [24] communication effectiveness is a critical element of ensuring organization and amalgamation within projects. Project management involves people at different levels of experience and responsibilities. A critical element in corporate projects success is communication procedure that specifies the capabilities and accountabilities clearly [25].

\section{Principles Regarding Effective Communication}

The challenging framework of communicating in the construction industry fosters questions regarding manner in which the industry can overcoming the cultural and structural circumstances and limitations that defines its operation, so that the industry can foster an organization that enables more effective and efficient communication moving forward. In order for the industry to overcome existing cultural constraints regarding development in the industry it needs to explore methods of effecting change required.

In theory, the method of utilizing communication effectively should be unambiguous, however the perspectives of theory and how they are actually interpreted for use is dependent on the people that work in the sector. Therefore, it is arguable that persons with experience working in the construction sector have developed skills to survive such a perplexing communication situation, that has allowed them to overcome the intrinsic difficulties of short to medium-term interface. Given that the construction sector is not static and involves people from varying disciplines to include managerial and professional backgrounds, there is no assurance that the use of good practices will have successful results.

\section{E. Channels of Communication}

Communication looks at the exchange of information at two levels, one being formal for example document exchange and second the informal which is problem-solving collaboration but this is restricted in construction projects 'Clear communication channels' was the sixth (6) element identified in an empirical study carried out by White and Fortune on the practices in project management for which a list of key success elements was identified. The main element being clear goals, objectives are also greatly dependent on well-defined and precise communication [26].

Project information is communicated through and uses many mediums such as the project office, face-to-face, video conferencing, documents for project planning, meetings, portals for the project, email, telephone and smartphone all of which can be viewed as tools or channels to communicate information. The most critical barrier that any construction company or any project faces is the issue of flow information that is vertical, lateral and downward, which is frequently dubbed as communication. The utilization of applicable flow of and the communication channel used to resolve problems in the construction stage and design stage are fundamental.

Amid an infrastructure projects, communication may take place in different ways subject to who is doing the communicating. Upward communication to management can occur from within the organization as well as from the client's organization, and lateral communication will occur with project teams and clients. Mechanisms need to be employed that would encourage communication downwards, that is from 
superior to sub-ordinate, or flat/horizontally between associates, and upward that is from minions to supervisors. As expressed by [27] more than one individual would be constantly included in communication.

\section{DATA ANALYSIS}

This study employed the use of a quantitative strategy as quantitative investigation utilizes an inferential methodology in connection to theory, which is concerned with sampling and measurement design [28]. Quantitative study is 'real' in nature. Described as an investigation aligned to a social or human issue, constructed on an assessment of a premise or concept comprised of anomalies, utilizing numeric measurement and analyzed using statistical methods to establish whether the premise or the concept holds true [29]. Quantitative data therefore isn't abstract, they are real and trustworthy; they are measurements of real, measurable, living features of the world [30].

If the following circumstances holds true then quantitative investigation/study can be selected:

In determining the truth about a model, an issue or an element.

In the gathering of real evidence, a study that is the association amongst these evidences in order to exam a specific proposition or concept

According to the objectives and the research questions, the questionnaire was designed and formulated in a way to obtain a wide range and as realistic as possible information from the infrastructure project professionals.

The Relative Importance Index (RII) method was utilized for this statistics investigation. [31] Utilized the Relative Importance Index (RII) method in order to establish the comparative significance regarding the numerous obstacles of effective communication and consequences of these obstacles. This technique was utilized in canalizing the diverse groups i.e. Architects, Civil, Structural and Mechanical Engineers, Project Managers, and Quantity Surveyors. A five-point measure that covers a range that starts at one (1) which symbolizes (not important) to five (5) which is (very important) was used and later relative importance indices Relative Importance Index (RII) was deduced for every element as shown below: was deduced for every element as shown below:

$$
\mathrm{RII}=\Sigma \mathrm{w} / \mathrm{A} * \mathrm{~N}
$$

Where, it is the respondents rating of every element covering an array from 1 to 5, " $\mathrm{A}$ " being the maximum rating, which is five and $\mathrm{N}$ the overall total of respondents. A Relative Importance Index (RII) ranges from 1 to 5 , the greater the value of Relative Importance Index (RII) reflects the significance of the impediment of effective communication.

Participants were requested to specify the regularity of the occurrence of the numerous categories of communication barriers, which occurred during project implementation until completion. The formula for frequency index was utilized to proportion the regularity of the occurrence regarding the impediments in communication recognized separately: (3) high,
(2) medium and (1) low. This investigation technique was utilized to determine the impediments in communication that take place in infrastructure projects.

$$
\text { Frequency Index }(\mathrm{F} . \mathrm{I})=\frac{3 \mathrm{n}_{1}+2 \underline{n}_{2}+\underline{n}_{3}}{3\left(\mathrm{n}_{1}+\mathrm{n}_{2}+\mathrm{n}_{3}\right)}
$$

The amount of participants that responded "high "is $n 1 ; n 2$ is "medium" and n3 is "low". is requested to scale the regularity of the incidence regarding the impediments in communication in accordance to ordinal measures: high (3), medium (2), and low (1). The Frequency Index (F.I.) of the individual sources was obtained using the frequency index formula above.

\section{EMPIRICAL DATA}

The questionnaire was made up of six sections with twenty-two questions. Section one covered the area of the participants' profile. Section two covered the area of project communication. Section three solicited the opinions of the participants on communication barriers in infrastructure projects in Jamaica whilst section four looked at communication management. Section five covered the area of the importance communication management skills needed and section six solicited the opinions of the participants in regards to which communication skill is important.

There were one hundred and forty (140) participants in the survey conducted that consisted of Architects, Contractors, Consultants, Project Managers, Managing Directors and Quantity Surveyors, which had a response rate of one hundred percent $(100 \%)$. In depth analysis was then carried out to ascertain respondents profile and job category as well as their knowledge of infrastructure project communication.

\section{A. Profile of Participants}

Section one consisted of questions in regards to the participants profile, gender, age group, years of experience, organization, profession, and their understanding of project communication.

Represented in figure $\mathrm{H}$ below are the demographic variables of this survey exercise. From these tables and charts it is shown that the questionnaires were completed as follows:

- $28.6 \%$ Project Managers

- $17.1 \%$ Contractors and Principal Consultants

- $14.3 \%$ Quantity Surveyors

- $7.9 \% \quad$ Managing Directors

- $7.1 \% \quad$ Architect

- $7.9 \%$ Others being Project Engineers and Site Supervisors

It was also noticed that thirty-seven point nine percent (37.9\%) had less than five years experience while the majority of sixty-two point one percent $(62.1 \%)$ had over five years experience in Infrastructure Projects. The operational 
involvement of the participants was deemed necessary for validating the responses to the questions posed. All the respondents that is, one hundred percent $(100 \%)$ knew what Infrastructure Project Communication entailed.

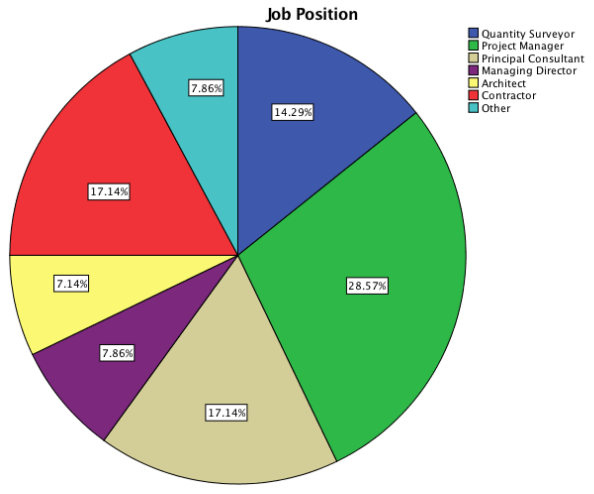

Fig. 1. Picture 1

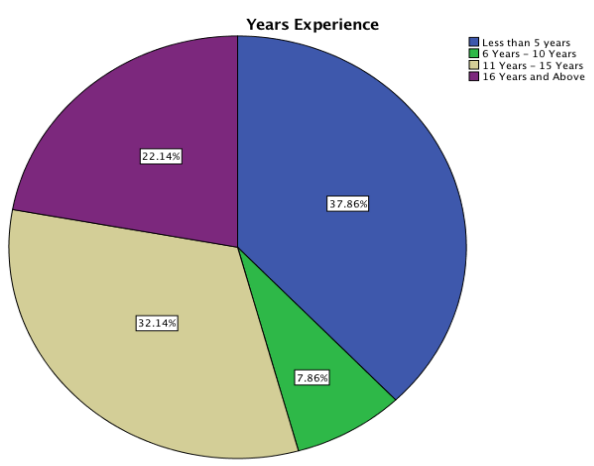

Fig. 2. Picture 2

\section{CONCLUSIONS AND RECOMMENDATIONS OF RESEARCH}

Summary of Findings: The conclusions of the study are presented in accordance to the objectives of the research and are as follows.

\section{A. The value of Project Communication by Project Professionals}

As per the answers received from the infrastructure project professionals in Jamaica's construction sector, there was an overwhelming understanding and appreciation for the management of project communication and its significance in the industry. In relation to certain communication matters there were common understanding of the significance of every component of communication on infrastructure project. For example, most of the participants concurred that important channel of communication are site meetings amid participants, customers, specialists, contractors and sub-contractors. All the participants regarded training of personnel is required for effective communication within infrastructure projects. The participants were also of the view that ineffective communication frequently results into abandonment, delays, cost overruns, including additional complications.

The participants also stated that poor and distorted information could impact the quality and quantity of work carried out. The failure of building components could be as a result of inexperience in understanding working drawings; distorted information is a result of ineffective means of communication. The significance of the language utilized between the various parties on site is vital for communication to be effective. Lastly the late distribution of communication will have a negative effect on work output.

Additionally, majority of the participants whom are infrastructure project professionals agreed to communication, which is on-going amid the project teams, and participants are very important or important in enhancing infrastructure project realization. The participants again concurred that open communication is necessary in order for management to have some control. The regular review and adjustments to the communication plan is seen as essential for project success, communication barriers and increase performance levels are overcome with the help of meetings, the establishment of communication procedures and approaches at the beginning of the project in order for infrastructure projects to be successful, project manager(s) to possess excellent communication skills so as to ensure that there is effective communication on infrastructure projects and lastly there ought to be a communication plan that illustrates the roles of stakeholders on infrastructure projects.

\section{B. Major Communication Barriers on Infrastructure Projects in Jamaica}

Including in the results of this study were the assorted barriers of communication on infrastructure projects in Jamaica. Poor listeners and leadership stood out as the utmost frequent obstacles to effective communication on infrastructure projects in Jamaica. Below are the more predominant barriers to effective communication on infrastructure projects, which are organized in descending order.

- Poor listener

- Ineffective reporting system

- Poor leadership

- Lack of trust

- Unclear

channels of communication

- Lack of concern

- Unclear objectives

- Information filtering
- Lack of necessary skills

$\stackrel{\bullet}{\text { typing }}$

Stereo

- $\quad$ Conflicting business /industry ethics

$$
\stackrel{\bullet}{\text { ed resources }} \text { Limit }
$$

- Political/comm unity interference

- Conflicting cultural values

$\stackrel{\bullet}{\bullet}$ Lang
age difficulties
$\stackrel{\bullet}{\bullet}$ Age
differences


Also the characteristics that are of importance and will increase effective communication management are the development of trust, partnership, cooperation and letting team associates assume accountability for work done and also distribution of the project concept with the various stakeholders and participants of the project.

Infrastructure project professionals with these characteristics are effective communicators and these features, if they are a part of their personality will form the style of how they lead project teams that is their leadership style.

These characteristics are people oriented, that is they focus on the project team and fits in with the McGregor's theory $\mathrm{X}$ and theory Y, Behavioral, Fiedler, Visionary and Situational management methods which concentrates on the situation and team.

Infrastructure project professionals need to surmise the condition, after which apply a method fitting to the condition i.e. situational management method, which is the best method for them to have during implementation of infrastructure projects. This allows for the team to be accountable for efforts made, cooperate and work as a group due to the fact they are cognizant of the concept of the project thus implying that project professionals trust the team participants.

\section{How Communication Management Affects Project Delivery, Project Quality and Cost Overruns Jamaica}

In respect to the purposes above, answers were only gathered from infrastructure project professionals in the sector. From the answers obtained it was recognized that poor communication management caused delays, cost overruns and abandonment. The same was recognized in respect to poor and distorted information dissemination, which too also affected the work performance level. That is to say, inexperience interpretation of working drawings had resulted in disasters in project delivery. From the results of the study it can be proven that communication management can have an adverse effect on project delivery.

\section{Stages in Which Communication Management Problems Occur}

The information and empirical data has established that, if communication problems were recognized in the construction stage, remedial measures can be established to increase efficiency. The manifestation of communication impediments during construction stage is rated the highest in the implementation of infrastructure projects. In detecting the stages that communication impediments happen, the project manager ought employ the best effective communication means avert alterations and impediments.

The communication means that are successful in increasing communication are written, oral, and electronic communication. The use of these means of communication thru project professionals or project manager(s) may avert the frequency of which communication impediments occur in the implementation of infrastructure projects and more particularly in the construction stage.

It has also been proven that project professionals ought be mindful in the utilization of electronic communication, but if care is taken and the message is planned, communication impediments can be averted.

\section{E. Determination of Hypothesis}

Hypothesis one of this research is expressed as follows:

Effective Communication Management will result in improved Project Quality and Project Delivery in infrastructure Projects.

Hypothesis one was deemed correct. The information and literature assessed illustrated that successful communication management can play a role to infrastructure project accomplishment. Although the ineffective utilization of communication methods/means can lead to obstruction, which in turn lends itself to a less fruitful result. Thus the understanding of the utmost important communication means/methods are hence a contributing factor to a projects accomplishment.

Penned communication is classified as the furthermost important communication methods/means to be utilized in implementation of projects. Penned communications is brief, inconspicuous, and precise and without uncertainty, which lends itself to improving communication while projects, are being managed. Oral communication is classified the second important form of communication methods/means and includes both telephone and face-to-face communication.

Electronic communication is classified third important mean of communication to be utilized in project management. Electronic communication includes the transmittal communications at a high rate to all participants that is stakeholders connected to the project.

Both written and electronic communications are of similar design, consequently spoken and all inscribed methods of communication are the utmost important methods/means utilized by project professionals as the correspondent in the implementation of projects. Also penned communication improves the usefulness of communication, as it can be used as evidence of what was completed while managing a project.

Hypothesis two of this research is expressed as follows:

Effective Communication Management will reduce Cost Overruns on Infrastructure Projects.

Hypothesis two was deemed correct. The information and literature assessed illustrated that successful communication management can positively impact areas such as time, quality and cost. Effective communication management involving areas such as cost will affect the accomplishment of infrastructure projects. Also communication regarding duration is ineffective then there will be a negative impact on the project including that of cost management. Similarly, if the management of communication is ineffective regarding quality management then the project will be negatively impacted in the areas of cost and time.

Therefore successful communication management by project professionals can impact in all areas, that is cost, quality and time positively, this will lead to the effective management of the infrastructure project as a whole. Effective 
communication is the basis and keystone of project management sections such as quality, scope, time and cost.

\section{F. Recommendations for future research}

There were a few limitations to this study, which should be considered once undertaking similar future research.

Firstly there were some gaps in the questionnaire that was administered. Areas such as;

- Academic qualifications of the respondents

- The inclusion of more communication channels

- Rating the possible influence of the infrastructure project professional communication abilities, overall success within the subsequent project management capacities:

- Project management integration

○ Project scope management

- Project time management

○ Project cost management

- Project quality management

- Project human resource management

○ Project communication management

- Project risk management

- Project procurement management

○ Management work-related health and safety

○ Ecosystem management

○ Economic management

- Management of claims

- How significant are the subsequent physiognomies that a infrastructure project manager ought to have to guarantee effective communication

○ Task co-ordination

$\circ \quad$ Following the rule book

- Permitting the team members to participate in process of making decision

- Involvement of the project team in the vision of the project

- People orientation

- Support for team members training and development

- Disclosing information to team members for the purposes of making decisions

- Setting challenges and goals for team members

- Developing trust, collaboration and teamwork

- Entrusting the team to make decisions themselves

- Permitting the team members to take accountability for work done
○ Realizing individual needs of team members

Secondly the selection of respondents was limited to only Grades 1 and 2 General Contractors for the expedience of time allotted to conduct the study.

Thirdly from administering the questionnaires to the respondents a few questions were asked which could also be considered as areas for future study.

- Can a standard be established to qualify the capability of a team or a person's main and significant effective communication skill to increase supervisory and management competences? Is there a model that can be utilized as a basis of quantifying communication management improvement and usefulness?

- Can a standard be established to quantify the development of main and imperative communication abilities of infrastructure project professionals? As it will illustrate zones of development as it relates to management and leadership.

According to the discoveries of this analysis the recommendation for future studies should be carried out in the following areas:

- The employment of a leadership and communication standard for infrastructure project professionals in Jamaica

○ How the use of effective communication management can mitigate against arbitration in infrastructure projects

- Defining the various ways of Informal communication and more precisely evaluating the value of informal communication in relation to the success of Infrastructure Projects

\section{CONCLUSION}

There is a resilience appreciation with regards to effective communication management and its importance within infrastructure projects in Jamaica. Undeniably, the many ranks and means of effective communications management has been recognized throughout the infrastructure projects sector, for instance effective communication management among clients and consultants, consultants and contractors and between various parties involved in infrastructure projects. All be it, numerous impediments have arisen that affect effective communication management in infrastructure project in Jamaica, included are; Poor listener, Ineffective reporting system, Poor leadership, Lack of trust, Unclear channels of communication, Lack of concern, Unclear objectives, Information filtering, Lack of necessary skills, Stereotyping, Conflicting business/industry ethics, Limited resources, Political/community interference, Conflicting cultural values, Language difficulties, and Age differences.

This study has recognized ineffective communication management impacted projects negatively resulting in delays, cost overrun and abandonment. 
Also illustrated is effective communication management can positively influence the functioning of infrastructure project professionals in the Jamaican infrastructure project sector.

Hence, prior to the implementation of any infrastructure project clearly established effective communication management structures along with management structure is of utmost importance matters that needs to scheduled by infrastructure project professionals and or team leaders.

The communication management skills adapted by infrastructure project professionals will improve communication and effective implementation of infrastructure projects.

These skills that will improve effective communication management in the implementation of infrastructure projects are making decision and solving problems, listening, meetings, motivation, team development building, management of conflict, explaining and writing.

Infrastructure project professionals whose characteristics or personality permits team participants to be accountable for work undertaken, cultivate faith, partnership, team work and also promotes project concept amongst the team ought to guide the team effectively and successfully as leader of the project and improve communication management within the project.

Application of the main communication management skills by the project leader in communication ought to communicate efficiently and effectively on infrastructure projects. In the application of communication management as the core purpose in the management of a infrastructure project in order for the delivery of a excellent product on schedule and within financial plan along with the assistance of the conveyance extents of human assets otherwise known as human resources (HR), risk mitigation, procurement, incorporation, entitlements, funding, well-being and security and also environmental management, the infrastructure project professional will improve infrastructure project results.

A standard or model for effective communication management and leadership is suggested as it will aid infrastructure project professionals in improving their capabilities to communicate effectively and efficiently, thus improving managerial and leadership skills therefore guaranteeing effective implementation and completion of infrastructure projects.

\section{ACKNOWLEDGMENT}

I would like to thank the following people/organisations for their support and effort:

- My Heavenly Father.

- My supervisor Dr. Li Yan for support and advice provided throughout this study.

- My family for support and belief in me.

- My colleagues at the Ministry of Health (Projects Dept.).
- The National Works Agency (Infrastructure Project Dept.).

- The Yunnan University of Finance and Economics, International Business School (IBS) for the study opportunities.

\section{REFERENCES}

[1] H. Emmerson. Survey of Problems Before the Construction Industries: A Report Prepared for the Minister of Works. London: HMSO,1962.

[2] G. Higgin. \& N. Jessop. COMMUNICATION ON THE BUILDING IINDUSTRY: The Report of a Pilot Study. 1st ed. London: Routledge, 2001

[3] M. Peltoniemi. and T. Jokinen. Communication Good practices in high technology Product Development Projects: Experiences from a Case Study. In: 1st ICEC \& IPMA Global Congress on project management, 5th World Congress on Cost Engineering, project management \& Quantity Surveying, 23 - 26 April, 2006,Ljubljana. Slovenia: ZMP, 2006.

[4] K. Henriksen. and E. Hansen. Kvalitet og byggefejl. 1st ed. Hørsholm: Statens Byggeforskningsinstitut.2006.

[5] J. Douglas. and W. Ransom. Understanding building failures. 3rd ed. London: Taylor \& Francis.2008.

[6] Bre.co.uk, BRE guidance on construction site communication. [Online]. Available from: http://projects.bre.co.uk/site_communications/pdf/communicationguidance.pdf, 2011.

[7] C. Cherry. On human communication: A Review, a Survey and a criticism. 3rd ed. Cambridge: MIT Press, 1978.

[8] M.W. Cummings. The Theory and Practice of Personnel Management. 6th ed. London: William Heinemann Professional,1989.

[9] H. Steyn. Project management. 2nd ed. Pretoria: FPM Publishing, 2012.

[10] Y. Chen. and J.M. Kamara. The Mechanisms of Information Communication on Construction Sites. FORUM EJournal, pp. 1 - 32, 2008.

[11] R.C. Shutt. Economics for the Construction Industry. 2nd ed. Essex, England: Longman Scientific and Technical,1992.

[12] G. Heyecan and K. Sima. Behavioral Aspects of Communication in Construction. In: The Construction, Building and Real Estate Research Conference of the Royal Institution of Chartered Surveyors, 2 -3 September, 2010, Paris: Dauphine Université, 2010.

[13] A. Aladeloba. H. Onukwube and A. Raheem, The effect of communication practice of construction companies on project performance. In: The Construction, Building and Real Estate Research Conference of the Royal Institution of Chartered Surveyors 2 -3 September, 2010, Paris: Dauphine Université, 2010.

[14] J. Sommerville, and N. Craig, Implementing IT in Construction. 1st ed. London: Routledge,2006.

[15] Association for Project Management .APM Body of Knowledge. 5th ed. Princes Risborough: Association for Project Management, 2006.

[16] M. Fielding, M. Effective communication in organisations. 3rd ed. Lansdowne, Cape Town: Juta Academic,2006.

[17] S. Emmitt \& C. Gorse. Construction Communication. 1st ed. Hoboken: Blackwell Publishing Ltd, 2003.

[18] S. Wilkinson, An analysis of the problems faced by project management companies managing construction projects. Engineering, Construction and Architectural Management, 2001, 8 (3), pp.160-170.

[19] British Standards Institution. Poor Communication Costing UK Construction Industry. [online] Available at: https://www.bsigroup.com/en-GB/about-bsi/media-centre/pressreleases/2003/9/Poor-Communication-Costing-UK-ConstructionIndustry/ [Accessed 14 Mar. 2018], 2003.

[20] V.E. Pitts, N.A. Wright, and L. Harbakus. Communication in Virtual Teams: The Role of Emotional Intelligence. Journal of Organisational Psychology, 2012, 12(3-4), pp. 21-34. 
[21] D.S. Nguyen. Success Factors for Building and Managing High Performance Global Virtual Teams. International Journal of Sciences: Basic and Applied Research, 2013, 9(1), pp. 72-93.

[22] R. Burke, Introduction to Project Management: One small Step for the Project Manager. U. K.: Burke Publishing,2007.

[23] J. Clements, and J. Gido. Effective project management. 5th ed. Mason, Ohio: South-Western/Cengage Learning, 2012.

[24] Spada Website, Construction

Communication, [Online]:http://www.spada.co.uk/property/construction-communication/, [Accessed 06 Apr. 2017]

[25] A. Knipe, Project management for success. 1st ed. Sandown, South Africa: Heinemann,2002.

[26] E. Van Staden, S. Marx, and L. Erasmus-Kritzinger, L. Corporate Communication: Getting the message across in Business. 1st ed. Pretoria: Van Schaik, 2002.
[27] M. Maslej, Communication in the Construction Industry [Diploma]. George Brown College, U.S.A, 2006

[28] S. Mohamed, and R. Stewart, An empirical investigation of users' perceptions of web-based communication on a construction project. Automation in Construction, 2003, 12(1), pp.43-53.

[29] J.W. Creswell, RESEARCH DESIGN Qualitative, Quantitative and Mixed Methods Approaches. 2nd ed. United States of America: Sage Publications, Inc,2003.

[30] G.D. Bouma, G.B.J. Atkinson, \& B.R. Dixon, B. R. A handbook of social science research. 2nd ed. Oxford: Oxford University Press.1995.

[31] S. Kometa, P. Olomolaiye, and F. Harris, Attributes of UK construction clients influencing project consultants' performance. Construction Management and Economics, 1994, 12(5), pp.433-443. 